\title{
O Golpe de 1964 e as Implicações sobre o Sentido do Desenvolvimento Capitalista Brasileiro
}

\section{The 1964 Coup d'Etat and its Implications on the Path of Brazilian Capitalist Development}

Leonardo Segura Moraes ${ }^{\mathrm{a}}$

\begin{abstract}
Resumo: O objetivo principal deste artigo é analisar os sentidos do golpe de 1964 sobre o desenvolvimento capitalista brasileiro e em quais bases materiais se assentaram. Para tanto, propõe-se a articulação das categorias trabalhadas por Jessop (1991) com a interpretação de Dreifuss (1981) sobre o golpe de 1964 no Brasil. A hipótese é que o golpe de 1964 ocorreu de uma crise do trabalhismo sem romper com a industrialização por substituição de importações. Conclui-se que o trabalhismo foi parte do projeto hegemônico oriundo da revolução de 1930, ao passo que o o desenvolvimentismo corresponde uma estratégia de acumulação do período.
\end{abstract}

Palavras-chave: Estratégias de acumulação. Projetos hegemônicos. Industrialização por substituição de importações. Golpe brasileiro de 1964.

Abstract: The main purpose of the paper is to analyze the meanings of the coup of 1964 on the Brazilian capitalist development and in which material basis it laid down. To do so, one proposes the link of the categories handled on Jessop (1991) with the interpretation of Dreifuss (1981) about the coup of 1964 in Brazil. The hypothesis is that the coup of 1964 occurred from a crisis of the laborism without breaking with the import-substitution industrialization. One concludes that trabalhismo (labourism) was part of the hegemonic project from the Revolution of 1930, whereas desenvolvimentismo (developmentalism) corresponds to an accumulation strategy of the period.

Keywords: Accumulation strategies. Hegemonic projects. Import-substitution industrialization. 1964 Brazilian coup d'état.

JEL Classification: N16; O38; P16.

\section{1 lntrodução}

A partir de 1930, inaugura-se uma nova fase do desenvolvimento capitalista brasileiro, pondo fim ao chamado modelo agroexportador. Nesse momento, no bojo do deslocamento do centro dinâmico da economia brasileira, tem-se o fato de que o mercado interno, puxado pela industrialização, exerceria cada vez mais sua força como centro dinâmico da acumulação no país. Politicamente, a novidade se deu na estruturação de uma nova correlação de forças que orientou a for-

Universidade Federal de Uberlândia (UFU), Instituto de Economia e Relações Internacionais. Uberlândia, Minas Gerais, Brasil. 
mulação da política econômica no Brasil e o novo sentido do desenvolvimento e suas instituições. A década de 1930, portanto, caracteriza-se por um momento de inflexão no desenvolvimento capitalista brasileiro, seja em torno das práticas que evidenciam por meio de uma nova gestão macroeconômica a intencionalidade industrializante dessa nova correlação de forças políticas e o clímax do processo de revolução burguesa (FONSECA, 2003; DRAIBE, 1985, p. 59-135; BASTOS, 2008; FERNANDES, 2011).

Esse conjunto de transformações sintetizadas se enquadra no contexto das políticas econômicas formuladas e executadas que se caracterizaram como projeto ou estratégia desenvolvimentista, as quais deram sentido à articulação entre Estado e sociedade civil no intuito de alterar conscientemente a realidade brasileira dentro dos marcos institucionais do capitalismo, grosso modo, entre 1930 e 1980. No entanto, ainda que seja possível identificar ao longo desse período a sustentação do cerne desenvolvimentista nos moldes tratados por Fonseca (2015), quais sejam, a existência de um projeto deliberado ou estratégia para a nação e seu futuro, o intervencionismo consciente e de acordo com o projeto e a industrialização como mecanismo central da acumulação e difusão do progresso técnico com vistas à transformação social: esse próprio desenvolvimentismo passou por diversas alterações em sua dinâmica. Dito de outra forma, ainda que o núcleo central da estratégia desenvolvimentista tenha se mantido, certos atributos secundários se alteraram significativamente em função da dinâmica que a política interna e do capitalismo internacional assumiram. Dessa forma, o artigo pretende interpretar em termos teóricos o golpe militar que derrubou o governo João Goulart e significou a recomposição das forças políticas do país. Seria possível, portanto, denominar o golpe de 1964 como uma inflexão do desenvolvimentismo brasileiro?

Responder essa questão implica definir categorias analíticas fundamentais para o estudo. Entretanto, é preciso antes fazer uma advertência metodológica sobre os pressupostos tomados aqui. Em primeiro lugar, entende-se que uma análise do sentido da política econômica só pode ser feita com base na inter-relação da Ciência Política com a Economia. Em segundo lugar, entender o sentido da política econômica significa analisar a correlação de forças políticas que se inter-relacionam com a base econômica e, dessa forma, acarretam disputas de interesses que se materializam sob a ação do Estado, que, por sua vez, não se caracteriza como um mero instrumento. Assim, aproximar-se-á das categorias trabalhadas por Jessop (1991) a fim de articulá-las com a perspectiva trabalhada por Dreifuss (1981) a respeito do significado do ano de 1964 para o desenvolvimento capitalista brasileiro. Propõe-se, portanto, responder as seguintes questões: a) qual é o sentido do golpe de 1964?; b) quais foram os aspectos econômicos que fundamentaram esse acontecimento?; c) qual a relação entre a política e a economia do golpe? Com isso, define-se o objetivo geral do artigo, que é apresentar os significados dos 
conceitos de estratégias de acumulação e de projetos hegemônicos à luz da experiência histórica brasileira entre 1964 e 1970.

A hipótese a ser trabalhada neste artigo é a de que o golpe de 1964 representa uma crise do projeto hegemônico constituído a partir de 1930, o qual tinha no trabalhismo um de seus eixos articuladores. O governo Goulart buscou restabelecer a correlação de forças políticas, mas não logrou êxito, e, dessa forma, o desenvolvimentismo brasileiro teve, em 1964, uma transformação, ainda que seu núcleo central de atributos continuasse o mesmo. As consequências dessa crise acarretaram um novo estilo de desenvolvimento e a formação de uma nova correlação de forças no seio do bloco no poder. Com isso, o novo bloco econômico multinacional e associado analisado por Dreifuss (1981) passou a ser também a liderança política do desenvolvimentismo brasileiro.

Para realizar o estudo, propõe-se uma revisão bibliográfica das interpretações do golpe e das respostas à crise dos anos 1960 na economia brasileira. Um importante eixo articulador dessas respostas se deu na questão da redistribuição da renda e na relação Estado-trabalhadores-mercado, caracterizada por Cardoso (2010) pelo conceito de cidadania regulada. Entende-se que o conceito de cidadania regulada está intimamente relacionado ao fenômeno do trabalhismo, os quais eram aspectos centrais do projeto hegemônico constituído a partir da revolução de 1930 e que entraram em crise com o golpe de 1964. A crise econômica do início dos anos 1960 representou o momento em que as forças políticas do novo bloco econômico multinacional e associado atuaram a fim de se impor politicamente contra a possibilidade de polarização favorável ao trabalhismo e buscando consolidar as demandas e interesses desse novo bloco econômico.

\section{A Crise do Trabalhismo e as Bases do Novo Projeto Hegemônico}

A especificidade da dinâmica assumida pela estrutura de classes no Brasil, oriunda do modelo agroexportador, acarretou fragilidade das oligarquias em se imporem hegemonicamente, o que afetou as possibilidades de efetivação da autonomia relativa do Estado frente às classes sociais a partir da crise desse modelo. Consequentemente, configuram-se os elementos constitutivos do processo de modernização conservadora no país em função das condições políticas para tal. Entre tais elementos, destacam-se a nova gestão macroeconômica, a qual subordinava as exigências dos credores externos às da expansão e diversificação internas, o antiliberalismo e o nacionalismo (BASTOS, 2008, p. 188; BASTOS, 2006). Porém, um elemento central desse processo reside nas transformações institucionais ocorridas, em especial no que diz respeito às relações de trabalho. Ao longo da década de 1930, e com destaque a partir do Estado Novo, a regulamentação das relações trabalhistas conviveu pari passu com a consolidação da dominação capi- 
talista industrial não por mero voluntarismo, mas como um imperativo histórico do processo de revolução burguesa no Brasil. O trabalhismo, portanto, emerge dessa conjuntura como aspecto central da política do Estado, não no sentido de privilegiar os trabalhadores em detrimento da burguesia industrial, ou vice-versa, mas essencialmente de promover uma tentativa de coesão das classes a partir do Estado (FONSECA, 1999, p. 428-464).

Para Cardoso e Faletto (2004), o trabalhismo, ou populismo trabalhista, assumido no Brasil se constitui como o mecanismo de expressão do modelo de desenvolvimento a partir de 1930 e cuja expressão é marcadamente urbana. Nas palavras dos autores:

No Brasil o populismo aparece como o elo através do qual se vinculam as massas urbanas mobilizadas pela industrialização - ou expulsas de setor agrário como consequência de suas transformações ou de sua deterioração - ao novo esquema de poder; e converter-se-á na política de massas, que tratará de impulsionar a manutenção de um esquema de participação política relativamente limitado e baseado principalmente em uma débil estrutura sindical que não afetou as massas rurais nem o conjunto do setor popular urbano (CARDOSO; FALETTO, 2004, p. 135).

Seria possível, portanto, caracterizar o trabalhismo como a tradução brasileira do projeto hegemônico a partir de 1930? É preciso antes uma compreensão do que se entende por projetos hegemônicos e sua relação com as estratégias de acumulação.

Para Jessop (1991), a unidade e a coerência substantiva dos Estados só podem ser de fato apreendidas a partir da complementação existente com os conceitos de projetos hegemônicos e estratégias de acumulação, pois a dinâmica da acumulação de capital depende do balanço existente das correlações de forças oriunda da luta de classes e da interação que esta tem com o arcabouço determinado pela forma-valor. Dessa forma, "coordenação" é a palavra-chave desse processo, em que os elementos centrais estão interconectados de maneira diferente de acordo com a esfera em análise, mas estão ligados organicamente ao longo do processo de reprodução da relação capital. Isto é, diferenciam-se na esfera de circulação, de valorização (produção) e de processo de trabalho. Ao tratar dessas questões, Jessop (1991, p. 141, tradução nossa) argumenta que "[...] estes elementos interconectados da forma-valor definem os parâmetros nos quais a acumulação pode ocorrer e também delimitam os tipos de crises econômicas que podem se desenvolver dentro do capitalismo [...]". ${ }^{1} \mathrm{O}$ conceito de estratégia de acumulação, portanto, é uma construção que busca conectar a teoria do capital com a teoria da classe, levando em consideração os fatores que condicionam a dinâmica

$1 \quad$ "These interconnected elements of the value form define the parameters in which accumulation can occur and also delimit the sorts of economic crises which can develop within capitalism" (JESSOP, 1991, p. 141). 
da acumulação. Entre eles, destacam-se, para Jessop (1991), as arbitrariedades da competição/concorrência, as conjunturas da luta econômica de classe, os sistemas legais e os sistemas políticos.

A construção do conceito de estratégia de acumulação se dá a partir da distinção de três aspectos, quais sejam, a dominação, a hegemonia e a determinação econômicas. O primeiro desses aspectos pode envolver várias frações do capital e se caracteriza pela capacidade de uma fração específica impor seus interesses econômico-corporativos particulares sobre as demais frações. O segundo aspecto corresponde à liderança econômica conquistada através da aceitação de uma específica estratégia de acumulação em um tipo de equilíbrio instável de compromisso. Por fim, o último desses aspectos diz respeito à metáfora superestrutura e infraestrutura, à la Althusser (1970), ${ }^{2}$ e quer dizer que os estágios superiores do "edifício" (superestrutura) não podem ser apreendidos de maneira isolada, mas precisamente sobre sua base econômica (material) fundante para a reprodução do sistema. Como definição do conceito, Bob Jessop afirma:

Uma "estratégia de acumulação" define um modelo completo de crescimento econômico específico com suas várias pré-condições extraeconômicas e esboça a estratégia geral apropriada para sua realização. Para ser bem sucedido, tal modelo deve unificar os diferentes momentos no circuito do capital (dinheiro ou capital bancário, capital industrial, capital comercial) sob a hegemonia de uma fração (cuja composição variará inter alia com o estágio do desenvolvimento capitalista) (JESSOP, 1991, p. 143, tradução nossa). ${ }^{3}$

De acordo com o autor, um dos exemplos mais típicos de uma estratégia de acumulação pode ser visto na industrialização por substituição de importações (JESSOP, 1991, p. 146), tipicamente implementada em vários países latino-americanos a partir dos anos 1930. Nesse sentido, não apenas os condicionantes internos foram preenchidos, mas a conjuntura internacional era propícia, tanto no que diz respeito ao balanço das lutas política e econômica de classe, quanto da margem de manobra estatal, dos capitais nacionais e filiais estrangeiras e também

2 Em um texto anterior, Althusser (2005, p. 85-116) trata de maneira pormenorizada dos significados da determinação econômica em última instância a partir da dialética marxista. Na verdade, o ponto central não é a determinação única, porém em última instância, algo reconhecido tanto por Marx quanto por Engels. É aqui que reside a verdadeira inversão da dialética de Hegel, que nada mais é do que uma substituição completa por outra dialética. Em realidade, a contradição não se dá meramente no plano econômico, pois ela é multifacetada, e aqui reside o papel da Ciência Política (ou das superestruturas, de acordo com a metáfora do edifício), a qual Althusser traz como grande trabalho o realizado por Gramsci.

3 "An 'accumulation strategy' defines a specific economic growth model complete with its various extra-economic preconditions and outlines the general strategy appropriate to its realization. To be successful such a model must unify the different moments in the circuit of capital (money or banking capital, industrial capital, commercial capital) under the hegemony of one fraction (whose composition will vary inter alia with the stage of capitalist development)". (JESSOP, 1991, p. 143). 
da ideologia vigente. Tal concepção teórica proposta pelo autor é de uma relação dialética entre estruturas e estratégias de acumulação, sendo que o sucesso da última dependerá da maneira pela qual se adaptará frente à margem de manobra oriunda da correlação de forças políticas internas. É aqui que a distinção entre estratégias de acumulação e projetos hegemônicos ganha forma.

Os projetos hegemônicos não se tratam apenas de relações de classe, mas englobam a construção de um ideário mais amplo. Apesar de ser conveniente uma estratégia de acumulação ser congruente com um projeto hegemônico, não é condição necessária essa aproximação. Para o sucesso do último, Jessop (1991) cita três fatores fundamentais: o primeiro é sua determinação estrutural, quer dizer, a relação com as formas de representação política existentes no Estado; o segundo diz respeito a sua orientação estratégia; e o terceiro é sua relação com o processo de acumulação. Em suma, o sucesso de um projeto hegemônico dependerá de sua capacidade de concessões materiais para as forças políticas subordinadas e a produtividade da economia. No entanto, sua prioridade não necessariamente precisa ser nos objetivos econômicos, ao contrário de uma estratégia de acumulação. Entre os objetivos que podem ser incluídos na construção de um projeto hegemônico, Jessop (1991, p. 153) exemplifica com sucesso militar, reformas sociais, estabilidade política e moralismo. Dessa forma, os projetos hegemônicos têm sua orientação principal no seio da sociedade civil, e não necessariamente nas relações de produção.

O conceito de hegemonia tratado por Jessop (1991) é o de interpelação e organização de frações de classe sob a liderança política, intelectual e moral de uma classe ou fração de classe específica. Mais do que isso, tal hegemonia concretizada em um projeto específico tem um papel essencial em manter a unidade substantiva dos aparelhos de Estado na condição de um conjunto institucional.

Resta ainda a questão central sobre a relação entre projetos hegemônicos e estratégias de acumulação: dado que os primeiros, quando bem-sucedidos, são aqueles que articulam uma relação orgânica entre base e superestrutura, isso significa que a força hegemônica é sempre uma classe ou fração de classe dominante? A resposta dada pelo autor depende do caso concreto, pois, se a liderança de formulação desse projeto se der a partir de intelectuais orgânicos, a resposta é negativa. Se ao contrário, a posição hegemônica advém de membros da classe econômica dominante, a resposta é afirmativa.

No Brasil, parece fazer sentido a associação de um projeto hegemônico específico (o trabalhismo) associado a uma estratégia de acumulação (a industrialização por substituição de importações - ISI) entre 1930 e 1964. Para justificar essa aproximação, pretende-se demonstrá-la à luz do conceito de cidadania regulada, aspecto típico do trabalhismo brasileiro oriundo dos anos 1930, tendo como base o estudo de Cardoso (2010). No caso da estratégia de acumulação, os argumentos 
favoráveis às práticas de intencionalidade industrializante e da nova gestão macroeconômica, as quais se combinam mutuamente, fornecem os subsídios para essa aproximação, como demonstram Fonseca (2003) e Bastos (2008). Por fim, a crise do trabalhismo, isto é, do projeto hegemônico oriundo da revolução de 1930, pode ser demonstrada pela incompatibilidade existente entre o novo bloco econômico multinacional e associado e a falta de liderança política por parte deste, especialmente a partir do governo JK e que ganha força na gestão de Goulart, como documenta Dreifuss (1981).

A cidadania regulada, tal qual Cardoso (2010, p. 788) mostra, é um conceito central para a compreensão da Era Vargas, pois, mais do que mera regulação do trabalho, tal cidadania se efetivava como um sistema de estratificação ocupacional regido pela lei, em que a carteira profissional de trabalho representava um verdadeiro certificado de nascimento. A cidadania regulada, em suas palavras, "[...] era um projeto para toda a nação a ser, porém, estendido aos nacionais à medida que cada qual se qualificasse, ou se enquadrasse no ideal de pessoa que o Estado queria promover [...]" (CARDOSO, 2010, p. 791). Dessa maneira, a sustentação desse sistema dependia do crescimento do emprego, concretizando a promessa de segurança socioeconômica pelo Estado. Por meio do aparelho estatal, a luta dos trabalhadores mudava de direção, indo naquele momento para a busca de efetivação, garantida pela Justiça do Trabalho e respaldada pela legislação trabalhista. Para mostrar a validade dessa tese, Cardoso (2010, p. 799) mostra que, até meados da década de 1960, cerca de 10 milhões de carteiras de trabalho foram emitidas, sendo que a população economicamente ativa (PEA) urbana se colocava abaixo dessa marca. Dessa forma, o autor conclui que a "inflação da crença" dos trabalhadores brasileiros "[...] na promessa de direitos, que gerou uma esperança de inclusão quase três vezes superior às possibilidades reais do mercado formal de trabalho urbano ao longo de mais de três décadas [...]" (CARDOSO, 2010, p. 798).

Isso não significa que a desigualdade foi rompida ou sua dinâmica estruturalmente superada. Como mostra Fonseca (1999, p. 296), a "questão social" para Vargas não era propriamente pautada na necessidade da redistribuição da renda como mecanismo do progresso social. Na verdade, o ponto central de seu projeto era a sustentação do desenvolvimento econômico com a garantia de direitos trabalhistas, em uma espécie de pacto entre classes sob a coordenação e tutela do Estado. Entretanto, a prática política de Vargas mostrou que, nos momentos de crise, ele buscou apoio nos trabalhadores, algo que, com a ascensão de Goulart, acirrou ainda mais o conflito político. O trabalhismo constitui-se, portanto, como elemento central do projeto hegemônico oriundo da revolução de 1930, mas, ao colocar a quase totalidade das classes dominantes contrárias à coesão, ou dividi-las, trouxe o fantasma da coerção à medida que ocorria o recrudescimento das reivindicações operárias. 
A cidadania regulada, portanto, caracteriza-se como um aspecto teórico e também empírico que ajuda a verificar a natureza desse projeto hegemônico construído desde 1930 e que entra em crise a partir do início dos anos 1960. Não desaparece, como mostram os dados de Cardoso (2010), mas altera-se profundamente o sentido de sua existência. A partir da Era Vargas, a legislação trabalhista passa a ser um direito, e não um privilégio, ou seja, institucionalizou-se a própria luta trabalhista. Esta, por sua vez, dependia claramente do sucesso da estratégia de acumulação em curso, qual seja, a da industrialização por substituição de importações. O pacto com os trabalhadores se deu, como mostra Fonseca (1999, p. 442), a partir da política salarial. Entretanto, a partir de 1964, essa política ganhou outros ares, muito menos favoráveis aos trabalhadores ou à garantia de promessa de segurança socioeconômica vigente durante o período do "populismo trabalhista".

A ruptura em 1964 marcou a derrota das reformas de base propostas pelo Plano Trienal e trouxe uma alteração institucional bastante significativa. Como mostra Costa (1997, p. 23), entre 1964 e 1966, 838 leis, 5.685 decretos-lei, 3 atos institucionais, 24 atos complementares, 41 resoluções do Banco Central (instituição recém-criada, inclusive), 476 regulamentos e 99 circulares do Ministério da Fazenda estão entre as mudanças legais promovidas pelo novo regime. Somam-se a essas alterações, as inúmeras intervenções em sindicatos, os expurgos do funcionalismo público civil e militar e as cassações de mandatos políticos ocorridas entre 1964 e 1979. Nas palavras do autor, tais ações tinham como objetivo, "[...] de um lado, excluir do processo político todos aqueles potenciais opositores do governo e, de outro, abrir espaço para a construção de um padrão de reprodução e acumulação do capital, cujo produto social foi a marginalização de milhões de brasileiros do mercado [...]" (COSTA, 1997, p. 26).

Alguns pontos essenciais nesse novo modelo desenvolvimentista se deram no incremento da taxa de poupança privada como mecanismo de financiamento dos investimentos, a melhoria da arrecadação tributária, a qual passaria a centralizar mais recursos para a União, e a nova política salarial imposta, a qual passaria a se adaptar ao ritmo da política monetária, isto é, o aumento salarial real só poderia se dar a partir de aumentos de produtividade (COSTA, 1997, p. 35). Os resultados dessa nova dinâmica da política salarial podem ser vistos nos números mostrados pelo autor, dado que, entre 1964 e 1985, a queda do nível do salário mínimo real ${ }^{4}$ em relação ao ano de 1964 foi da ordem de 43,5\% (COSTA, 1997, p. 41). O processo da concentração de renda, característico desse período, pode ser visto nos dados trabalhados pelo autor. Em 1960, os 10\% mais ricos da população,

$4 \quad$ Schlabitz (2014 , p. 102) fornece uma evidência a partir da análise econométrica de quebra estrutural dinâmica do salário mínimo. De acordo com a autora, a partir de 1966 o reajuste do salário mínimo se deu sob outra institucionalidade legal e provocou uma redução sistemática de seus níveis até 1986. 
apropriavam-se de cerca de $40 \%$ da renda. Já em 1984, esse mesmo percentil se apropriava de 48\% da renda (COSTA, 1997, p. 56).

As evidências sugerem, portanto, que a partir do golpe de 1964, outra dinâmica da relação Estado-empresários-trabalhadores se instituiu, na qual o modelo trabalhista de acomodação dos interesses e, eventualmente, fortalecimento dos interesses dos trabalhadores foi substituído por um no qual a tônica do processo se dava no aumento de produtividade e na concentração de renda. Para Mello e Belluzzo (1977, p. 147), resumidamente pode-se dizer a respeito desse tipo de política que "[...] o arrocho salarial contemplava diferencialmente os vários interesses capitalistas, porém, de uma forma geral era compatível com todos eles, inclusive com os do próprio governo, empenhado em comprimir seus gastos correntes [...]".

Em oposição aos anos JK, entre 1968 e 1974, a dinâmica do crescimento se deu com base na estrutura preexistente em sua grande maioria, invertendo o sentido da equação do crescimento econômico anterior. O eixo da acumulação, portanto, passou a se dar com base no setor de bens de consumo duráveis, e não sobre os bens de produção. Todo esse processo é consequência das alterações implementadas pelo Programa de Ação Econômica do Governo (Paeg), o qual caracterizou o recurso ao financiamento via emissões primárias como não mais essencial em virtude da maior elasticidade do sistema tributário a partir de então. Dessa forma, o financiamento dos gastos pode-se dar acima do crescimento do produto. Nesse momento em que a dominância da acumulação se deu nos bens de consumo duráveis, impôs-se uma forte diferenciação nos salários e contenção do salário mínimo, como mostrado anteriormente pelos dados de Costa (1997). Isso advinha, evidentemente, do diagnóstico e do receituário feito pelo Paeg frente à crise do início dos anos 1960, os quais geraram um descompasso de realização dinâmica, como tratam Mello e Belluzzo (1977). De certa forma, tais mudanças se relacionam intimamente com a ascensão política do novo bloco econômico multinacional e associado, como ilustra bem a reformulação da Lei de Remessa de Lucros no contexto do Paeg (1964-1967), "[...] cedendo ao capital externo generosas condições de expatriação de rendimentos [...]” (MELLO; BELLUZZO, 1977, p. 146).

\subsection{Causas do Golpe de 1964: Interpretações ${ }^{5}$}

Fico (2004) identifica dois gêneros interpretativos na literatura sobre o golpe militar de 1964, os quais lidam diferentemente com as causas e significados desse episódio histórico. Em primeiro lugar, há o gênero de interpretações centradas

5 É importate notar que o debate historiográfico sobre o golpe de 1964 tem avançado nos últimos anos, com destaque para o ano de 2014, que marcou os 50 anos desse fato histórico. Para um aprofundamento dessas questões, ver, por exemplo, Ferreira e Gomes (2014). 
na vertente estadunidense da Ciência Política e que busca explicar e classificar o golpe como um fenômeno intrinsicamente militar. O segundo desses gêneros se caracteriza pela memorialística sobre o golpe e a ditadura conseguinte, revelando certos estereótipos e/ou mitos idealizados, tais como o do perfil moderado e legalista de Castelo Branco e o do guerrilheiro ingênuo e romântico dos anos 1960-70.

Tomando o primeiro gênero, sua teorização apresenta autores como Alfred Stepan, Wanderley Guilherme dos Santos, Maria Celina D'Araújo e Angelina Cheibub Figueiredo, entre outros. Fico (2004) sintetiza as principais ideias desse gênero interpretativo, tais como a ideia de Stepan de que o subsistema militar viveu um período moderador entre a sociedade civil e o Estado, mas a incapacidade de Goulart em reequilibrar o sistema político associada às insatisfações próprias dos militares naquela época (quebra de disciplina e de hierarquia) levaram ao golpe e à instituição de forças militares no poder. Já Wanderley Guilherme dos Santos procurou mostrar que a extrema polarização política do período levou a uma "crise de paralisia" e propiciou a ascensão militar como forma de solucionar esse impasse. Por outro lado, a leitura de Angelina Figueiredo é a de que o golpe não era inevitável nem se deriva de uma conspiração burguesa, mas do estreitamento de opções políticas oriundo de escolhas anteriores, as quais impossibilitaram a viabilização democrática das reformas propostas por Goulart. Em suma, nas palavras de Fico (2004, p. 48), esse conjunto de interpretações evidencia uma visão sobre o golpe em que "[...] a Ciência Política de influência norte-americana, ao enfatizar os aspectos político-institucionais e as variáveis políticas, contrapunha-se às leituras marxistas que destacavam as determinações econômico-estruturais e os condicionamentos de classe [...]".

As análises marxistas, por sua vez, não se restringiram a uma mera interpretação economicista ortodoxa que não levasse em consideração o papel da política no processo. Nesse sentido, Fico (2004) destaca a ideia de Jacob Gorender de que o golpe ocorreu em virtude do estágio avançado do capitalismo brasileiro e serviu como ação preventiva contra possíveis ameaças revolucionárias da esquerda. Já Dreifuss, como mostra Fico (2004), argumenta que o golpe funcionou para a constituição de um bloco de poder a partir da consolidação de um novo domínio econômico do capital multinacional e associado, o qual se formou entre os governos JK e Jânio Quadros, mas ainda não detinha a liderança política do processo de acumulação de capital. Outro desses intérpretes marxistas, Daniel Aarão Reis Filho, destaca que, além das associações no seio das classes dominantes, evidenciadas pela pesquisa de Dreifuss (1981), o papel da classe média foi fundamental para o apoio ao golpe, pois via sua posição social ser colocada em xeque pelos potenciais processos de redistribuição de renda propostos àquela época.

Por fim, há as interpretações que valorizam o papel dos militares no processo. Suas principais ideias advêm de pesquisas através de entrevistas com militares 
atuantes no processo da ditadura e se percebe que a ordem dos fatos foi uma conspiração militar com o apoio dos grupos econômicos no Brasil, não o contrário, como sugerem as interpretações marxistas. Nesse sentido, as motivações militares se sobrepunham às econômicas, isto é, o caos administrativo e político, o perigo comunista e os ataques à hierarquia e disciplinas militares aparecem como motivos centrais para a ruptura política em 1964 nesse conjunto de interpretações. Caracteriza-se, portanto, um golpe essencialmente político, como afirma Gláucio Ary Dillon Soares. Por meio dos depoimentos dos militares, revela-se uma visão de que o golpe dependeu fundamentalmente de alguns nomes-chave para a mobilização das tropas, como o do general Amaury Kruel, comandante do II Exército. Mostra-se, também, o caráter menos articulado do que até então se imaginava entre os distintos atores sociais do processo golpista.

Frente às distintas formas de interpretar o fenômeno golpista em 1964, Fico (2004) tenta uma síntese das contribuições a fim de apreender a capacidade explicativa dos argumentos. Nas palavras do autor,

Sem a desestabilização (propaganda ideológica, mobilização da classe média, etc.) o golpe seria bastante difícil; sem a iniciativa militar, impossível. Portanto, é preciso bem distinguir a atuação desestabilizadora (a propaganda do IPES e outras agências) da conspiração golpista civil-militar, que em muitos momentos não passou de retórica radical e somente se consolidou às vésperas do 31 de março. Assim, creio não ser abusivo afirmar o acerto histórico da leitura segundo o qual a "desestabilização civil" foi bastante articulada, mas a ação militar não foi inteiramente planejada, com segurança e sistematicidade, ficando à mercê de iniciativas de algum modo imprevistas (FICO, 2004, p. 55).

Caracterizar o golpe como um fenômeno político não representa plenamente as questões em curso do momento histórico, pois, além das razões mencionadas, há componentes econômicos oriundos dos conflitos do início da década. Para Bastos (2014), esses problemas macroeconômicos se originam como consequência do Plano de Metas e da aceleração do crescimento. Em síntese, cinco problemas macroeconômicos surgem e ajudam a explicar as razões econômicas da crise e do golpe de 1964. O primeiro diz respeito à sustentação da demanda agregada após a maturação dos investimentos e a consequente redução do crescimento. $\mathrm{O}$ segundo se associa aos desequilíbrios na balança de pagamentos em virtude da queda nos preços do café (ainda importante produto exportado e fonte de divisas externas) e ao aumento nas remessas de juros e lucros. Em terceiro lugar, houve a aceleração inflacionária oriunda da crise cambial, dos déficits públicos e estrangulamentos setoriais. Consequentemente, há o conflito distributivo como quarto problema macroeconômico, cuja origem se dá tanto na crise cambial e na inflação em alta, porém esse conflito ocorria principalmente no aumento das margens de 
lucros e na reação dos oligopólios frente à depreciação cambial. Por fim, o déficit fiscal com origem na corrosão dos tributos em função da aceleração inflacionária.

A mobilização política dos grupos sociais se dava articuladamente com o conflito distributivo, pois a estagflação atingia diferentemente os grupos sociais. Especialmente a pequena burguesia e os setores médios urbanos tradicionais experimentavam uma ameaça às suas respectivas posições sociais e renda real com o processo de estagflação. Para Bastos (2014, p. 14), “[...] o objetivo do golpe foi barrar a onda democratizante e defender o status quo. A saída da crise econômica era uma questão relacionada [...]”. Dessa forma, o conteúdo político da crise econômica se mostra também a partir da conjuntura econômica, com destaque para a questão da distribuição da renda. A partir de 1964 e da nova política salarial, tais ameaças seriam amenizadas.

De maneira geral, é possível, portanto, compreender os elementos constitutivos do novo projeto hegemônico com a origem em 1964 e a ruptura militar. O primeiro desses elementos é a nova dinâmica da distribuição da renda do trabalho em função da política salarial que surge com o Paeg. O segundo elemento central é a ascensão como liderança política por parte do novo bloco multinacional e associado que se fortalece desde o governo $\mathrm{JK}$, realizando pressões sobre o bloco no poder. Na próxima seção, tratar-se-á da interpretação mais detalhada de Dreifuss (1981) e como tal leitura pode ser associada com os conceitos de Jessop (1991).

\section{Golpe de 1964 e a Constituição de um Novo Bloco no Poder}

A natureza da crise dos anos 1960 foi objeto de amplas discussões entre os cientistas sociais e historiadores e, como visto na seção anterior, associada em grande parte aos desdobramentos políticos que acarretaram no golpe de 1964. De uma maneira geral, essa crise pode ser vista por aqueles que entendem como uma tendência à estagnação econômica em função da concentração de renda e da propriedade, gerando um argumento com forte viés subconsumista, tal qual apregoara Celso Furtado naquela época. Por outro lado, tomando Tavares e Serra (1973) como leitores desse período, tal crise estava estruturalmente relacionada ao esgotamento do processo de substituição de importações. ${ }^{6}$ Nesse sentido, a economia brasileira necessitava complementar esses investimentos do Plano de Metas com novos que representassem uma onda de inovações, isto é, alinhassem a eco-

6 O debate sobre o estagnacionismo econômico dos anos 1960 apresenta referências envolvendo autores à direita e à esquerda do espectro político. Destacam-se, por exemplo, Oliveira (2003) sobre a incapacidade de superação teórica da economia de mercado por parte dos estruturalistas naquela época e Simonsen (1970) a respeito da dinâmica inflacionária brasileira do período e das opções de política econômica em jogo frente a uma tendência inercial do fenômeno. Além disso, no caso de Oliveira (2003), o conceito de padrão de acumulação utilizado pelo autor se aproxima ao de estratégia de acumulação oriundo de Jessop (1991). 
nomia brasileira com o padrão tecnológico e de produtividade existente nos países avançados. Como isso não ocorreu no tempo adequado, o país ficou suscetível a flutuações cíclicas oriundas do próprio processo de desenvolvimento incompleto ou parcial. Em suas palavras:

No caso do Brasil, pode-se dizer que a crise econômica de meados da década passada [1960] expressa também - como já foi dito - uma transição, não a uma nova economia mas a um novo estilo de desenvolvimento capitalista que supõe, dada a existência de uma base produtiva adequada, um novo esquema de concentração de poder e da renda, bem como novos mecanismos de estímulo, adequados a outra etapa da integração com o capitalismo internacional (TAVARES; SERRA, 1973, p. 175).

Os problemas centrais identificados pelos autores eram na estrutura de demanda e de financiamento, com destaque para a distribuição concentrada da renda e a elevada relação gastos-carga fiscal. A solução levada à frente após o golpe foi a de alterar a composição da demanda por meio de redistribuição da renda a favor das camadas médias e altas e comprimindo os salários de base. Sobre a questão do financiamento, o ponto central não era apenas a quantidade de recursos, mas fundamentalmente a maneira pela qual seriam financiados os novos projetos, e, para tanto, buscou-se não mais o esquema inflacionário vigente até então. Dessa maneira, mesmo que o crescimento econômico tenha sido reduzido na primeira metade da década dos anos 1960, o processo de desenvolvimento capitalista não se interrompeu, e, como visto anteriormente, a dinâmica da acumulação passou a se dar no setor de bens de consumo duráveis, notadamente entre 1967 e 1970.

Tavares e Serra (1973, p. 205-206) reconhecem que as respostas frente à crise do início dos anos 1960 consubstanciada pelo Paeg a partir de 1964 implicou uma reorganização da dinâmica do desenvolvimento capitalista, dos mecanismos internos de poder e da articulação com o capitalismo internacional. Nesse sentido, o golpe de 1964 pode ser visto como uma etapa de reconfiguração do bloco no poder, rompendo com o projeto hegemônico trabalhista até então. Como foi visto na seção anterior, um elemento central desse rompimento e da construção do novo projeto hegemônico está intimamente associado a nova política salarial e à relação Estado-mercado-trabalhadores nessa nova etapa.

Poulantzas (1986), ao tratar do conceito de bloco no poder, coloca-o como um fenômeno relacionado às práticas políticas das classes dominantes no sistema capitalista, mas depende fundamentalmente da pluralidade de interesses entre as diversas frações de classe dominante existentes, algumas inclusive conflitantes em vários aspectos. Trata-se de um conceito relacional entre as classes e inscrito na estrutura do Estado. Sua dinâmica se relaciona com a periodização do desenvolvimento capitalista e cumpre uma função semelhante à do conceito da forma de Estado no âmbito da superestrutura (POULANTZAS, 1986, p. 229). Não se trata de 
uma aliança de frações da classe dominante, embora haja unidade e contradição tanto no conceito de aliança quanto no de bloco no poder. A diferença entre eles se dá na natureza dessa contradição, pois no caso do bloco no poder é possível identificar as distinções entre classes e frações que o compõe de maneira clara. Além disso, no caso do bloco no poder há sacrifícios de interesses mútuos entre seus membros em todos os níveis da luta de classe, ao passo que, no caso da aliança, percebe-se um nível determinado, específico, a um campo da luta de classes e, portanto, caracteriza-se como um fenômeno mais pontual.

Pensando concretamente no caso brasileiro, a especificidade da revolução burguesa em um contexto dependente e de capitalismo tardio acarretou uma dinâmica política específica. Como foi delineado, a crise do modelo agroexportador no Brasil implicou ausência de hegemonia específica, a qual a partir de 1930 propiciou uma transformação no sentido da atuação estatal. Para Dreifuss (1981, p. 75), a tônica do regime militar no Brasil e o sentido do planejamento levado à frente a partir do golpe de 1964 tinham como objetivo a nação (o fim das ações), o agente sendo o Estado e o bloco econômico multinacional e associado, o sujeito (ainda que oculto). Dessa forma, constituiu-se o novo bloco no poder pós-1964, criando, com base nessa formação político-econômica, um conceito de planejamento que traduzia os interesses das classes dominantes de maneira racionalizada e tornava tais interesses como nacionais. Esse processo se deu, de acordo com o autor, ainda no Plano de Metas. Em suas palavras:

Os interesses multinacionais refratavam-se no processo decisório governamental através do Plano de Metas como necessidades do desenvolvimento nacional. Assim, o poder de classe era internalizado no Estado sob a cobertura de racionalidade técnica, necessidade e perícia (todos eles com conotação neutra), e legitimado por grupos executivos e pelos escritórios de consultoria tecno-empresariais. Além disso, sob a égide da "racionalidade" técnica, os empresários justificavam o seu processo de tomada de decisão subjacente, assim como a sua escolha das diretrizes políticas referentes ao desenvolvimento (DREIFUSS, 1981, p. 76).

Para construir a base empírica que evidencia essa solidariedade de interesses no seio do novo bloco econômico em vias de se constituir como liderança política do processo de desenvolvimento brasileiro, Dreifuss (1981) identifica as diferentes estruturas políticas que expressavam os interesses desse bloco. Em primeiro lugar, havia os escritórios de consultoria tecno-empresarial (Consultec, Consórcio Brasileiro de Produtividade (CBP), entre outros). A função dessa estrutura técnica consultiva era, como primeiro estágio de consciência empresarial coletiva, nos membros individuais das classes dominantes e, como segundo estágio de tal consciência, a busca deliberada por reformas econômicas por meio dos aparelhos de Estado que fossem de acordo com os interesses privados constituídos. Nesse sentido, destaca-se a articulação dessas consultorias e o aparelho de Estado, por 
exemplo, na interação existente entre o CBP e o Banco Nacional de Desenvolvimento Econôminco (BNDE) para estudos e assessoria específicos. Além disso, Roberto Campos naquela época (1958-1959) era presidente do BNDE e membro da Consultec. Esta, por sua vez, foi a responsável pelo surgimento da organização tecno-empresarial e político-burocrática Análise e Perspectiva Econômica (APEC), a qual se ligou a inúmeros políticos-chave e a aparelhos estatais, tal como, a Mario Henrique Simonsen, João Paulo dos Reis Velloso Escritório de Planejamento Econômico e Social (EPEA), Raul Fontes Cotia e Ernane Galvaes (ambos do BNDE), entre outros.

Em segundo lugar, Dreifuss (1981) destaca o papel das associações de classe empresariais (Federação das Indústrias do Estado de São Paulo - Fiesp, Centro das Indústrias do Estado de São Paulo - Ciesp, Associação Brasileira da Infraestrutura e Indústrias de Base - Abdib, Conselho Superior das Classes Produtoras - Conclap, American Chambers of Commerce, entre outras). Os intelectuais orgânicos dessas associações de classe empresariais se expressavam por meio das publicações ligadas a elas (por exemplo, a revista Digesto Econômico) e fóruns específicos (por exemplo, o Conselho Técnico de Economia, Sociologia e Política da Federação do Comércio do Estado de São Paulo). Dessa maneira, tais associações classistas orientaram empresários e funcionaram como verdadeiras agências de lobbying (DREIFUSS, 1981, p. 93). Outro elemento de força dessas associações se deu pelo apoio transnacional dos Estados Unidos por meio de intervenções diplomáticas favoráveis a companhias estadunidenses no Brasil, tal como nos casos da Hanna Mining Co. e da ITT. Havia, também, apoio extraoficial através de iniciativas de mobilização e influência na comunidade de empresários brasileiros por meio de diversas instituições, com destaque para a American Economic Foundation (AEF), o Business Group for Latin America e o Council of the Americas (DREIFUSS, 1981, p. 100-101).

Por último, havia ainda os grupos de ação política e ideológica que expressavam esses interesses privados empresariais e buscavam a articulação no Estado, dentre os quais se destacavam o Instituto de Pesquisas e Estudos Sociais (Ipes) e o Instituto Brasileiro de Ação Democrática (Ibad), objeto direto de estudo de Dreifuss (1981). Esses grupos atuaram decisivamente ao longo da formulação do Paeg, programa econômico de enfrentamento da crise do início da década dos anos 1960 e que consolidou as bases da continuação do processo de industrialização por substituição de importações. No entanto, ainda que tal estratégia de acumulação persistisse, não mais se daria da mesma forma que no período anterior, visto que o próprio estilo de desenvolvimento pelo qual o país iria se encaminhar havia mudado. Tal aspecto denota, portanto, que a dinâmica de estruturação do projeto hegemônico não mais era a mesma se o entendemos à luz dos conceitos trabalhados anteriormente. Com isso, não mais o trabalhismo guiaria as ações do Estado 
ou a maneira pela qual institucionalmente a relação capital-trabalho se daria. A partir de então, a infiltração ideológica e concreta nas práticas políticas pós-1964 evidencia um projeto hegemônico sob a égide dos interesses e das práticas políticas tecno-empresariais. Nas palavras de René Dreifuss:

Dois períodos podem ser destacados no processo político e ideológico
através do qual os interesses multinacionais associados e seus intelectu-
ais-empresários, políticos e militares - assumiram o controle do Estado.
O primeiro período, usando uma expressão de Gramsci, foi de "transfor-
mismo molecular". Foram criados anéis burocrático-empresariais, escri-
tórios técnicos e centros burocráticos e militares de doutrinação e disse-
minação ideológica, os quais se interligaram na sua visão programática
das reformas de Estado necessárias formando os incipientes intelectuais
orgânicos do bloco de poder multinacional associado. Ao mesmo tempo
que isso acontecia, o bloco histórico populista dava sinais de exaustão
política (DREIFUSS, 1981, p. 106).

Verifica-se, então, que o projeto do populismo trabalhista não conseguiu agir de forma a se sustentar em suas linhas gerais, quais sejam, o Estado agindo como mediador da expansão capitalista intencional de suas políticas econômicas e ao mesmo tempo valorizar a força de trabalho (FONSECA, 1999, p. 458). Os sentidos do golpe de 1964, portanto, mostram uma cristalização dessa nova correlação de forças políticas, cujo produto pode ser visto na formulação de um novo projeto hegemônico, o qual, por sua vez, ditou a dinâmica pela qual o estilo de desenvolvimento capitalista brasileiro iria seguir a partir de então. Os pilares desse novo projeto hegemônico podem ser vistos na nova política salarial, que realizou uma verdadeira concentração de renda e desvalorização do salário mínimo real, na centralização de recursos tributários nas mãos da União e no fortalecimento do papel repressor do Estado. Dessa forma, os valores do novo bloco econômico multinacional e associado passaram a liderar também o novo bloco no poder e a redefinir o papel do Estado e dos trabalhadores nesse processo. Como mostram Mello e Belluzzo (1977, p. 150), o sentido do intervencionismo estatal após 1964 é o de acentuar "[...] seu papel de mobilizador e concentrador de excedente, mas apenas age como um mero repassador de fundos ao setor privado [...]”.

Essa nova dinâmica política e econômica fica mais clara ao se comparar com o último suspiro do projeto hegemônico trabalhista sob o governo de Goulart. Como mostra Fonseca (2004), a política econômica conduzida ao longo da gestão Jango possuía racionalidade e lógica próprias, sendo, portanto, pouco evidente um suposto caráter errático da política econômica nesse período. Dessa forma, duas palavras definem a periodização desse momento histórico: legitimidade e credibilidade. $\mathrm{Na}$ verdade, a busca pela legitimidade governamental trazia consigo, pelo menos em parte, uma tentativa de restabelecer o equilíbrio de forças políticas do bloco trabalhista. Os momentos de credibilidade sugerem as tentativas 
de fornecer concessões no âmbito do bloco no poder, porém as turbulências se intensificaram com a crise e o consequente fortalecimento do novo bloco econômico. As reformas estruturais propostas no Plano Trienal, a Lei de Remessa de Lucros e a encampação de empresas estrangeiras constituíram mudanças institucionais que contrariavam profundamente os interesses desse novo bloco econômico multinacional e associado e, portanto, acarretaram rompimento com a ordem vigente, muito mais do que a condução das políticas econômicas meio ou instrumentais (FONSECA, 2004, p. 619-620).

\section{Considerações Finais}

Com base no que foi exposto ao longo deste artigo, buscou-se responder as perguntas feitas na introdução a respeito dos sentidos do golpe de 1964. Para tanto, procurou-se aproximar os conceitos de estratégias de acumulação e projetos hegemônicos à luz da experiência concreta brasileira desse período e da transição do governo Goulart para o regime civil-militar inaugurado com o golpe. Responder a primeira questão, de caráter mais amplo, parece possível com base nos argumentos aqui levantados. Isto é, 1964 pode ser visto como uma inflexão no desenvolvimentismo brasileiro, dado que a partir de então o estilo pelo qual o desenvolvimento seguiu foi profundamente alterado. No entanto, qual tipo de mudança ou inflexão é possível observar?

De uma maneira geral, a articulação de interesses e de correlação das forças políticas acarretou uma tensão no seio do bloco trabalhista, a qual tem origem na própria dinâmica do desenvolvimento, em especial a partir do período JK. A estratégia de acumulação, entretanto, manteve-se a mesma, qual seja, a industrialização por substituição de importações. Por outro lado, o estilo de desenvolvimento alterado a partir de então parece intimamente relacionado à nova configuração da correlação de forças políticas e da crise do trabalhismo. Dessa maneira, o projeto hegemônico que nasce com a revolução de 1930 e tem como fundamentos a expansão capitalista aliada a certos avanços nos interesses trabalhistas, porém sob a tutela e mediação ativa do Estado, rompe-se. Com base nisso, as novas forças econômicas revelam sua ambição de compatibilizar a liderança econômica com a política, especialmente através das novas estruturas políticas originadas desse período, tais como os escritórios técnicos, os grupos de ação e as entidades de classes empresariais. De certa forma, esse novo projeto hegemônico se constitui com base nesse conjunto ideológico tecno-empresarial, em substituição às pretensões trabalhistas dos governos anteriores. Isso se evidencia no novo estilo de desenvolvimento pós-1964, cuja concentração de renda, desvalorização do salário mínimo (de base) e fortalecimento do aparelho repressor do Estado ganham força e impõe-se como prática política do novo bloco no poder. 
Os aspectos políticos e econômicos desse processo, sua interrelação e a validade da política como elemento explicativo da transição revelam-se nessa articulação de conceitos e realidade concreta. A resolução do conflito distributivo implicou intensas disputas de interesse, as quais mostram que o estilo de desenvolvimento, isto é, o modo pelo qual o excedente será canalizado, depende da política e não apenas da economia (tecnologia, produção). O golpe de 1964 caracteriza, portanto, uma mudança nesse estilo de desenvolvimento no bojo da construção de um novo projeto hegemônico dentro da estratégia de acumulação desenvolvimentista.

\section{Referências}

ALTHUSSER, L. Idéologie et appareils idéologiques d'État. La Pensée, n. 151, 1970.

ALTHUSSER, L. Contradiction et surdétermination. In: ALTHUSSER, L. Pour Marx. Paris: La Découverte/Poche, 2005. p. 85-116.

BASTOS, P. P. Z. A construção do nacional-desenvolvimentismo de Getúlio Vargas e a dinâmica de interação entre Estado e mercado nos setores de base. Revista Economia, v. 7, n. 4, p. 239-275, 2006.

BASTOS, P. P. Z. Ortodoxia e heterodoxia antes e durante a Era Vargas: contribuições para uma economia política da gestão macroeconômica nos anos 1930. Revista Economia, v. 9, n. 4, p. 183-214, 2008.

BASTOS, P. P. Z. Razões econômicas, não economicistas, do golpe de 1964. Texto para Discussão, IE/UNICAMP, n. 229, p. 14, 2014.

CARDOSO, A. Uma utopia brasileira: vargas e a construção do Estado de bem-estar numa sociedade estruturalmente desigual. Revista de Ciências Sociais, v. 53, n. 4, p. 788-799, 2010.

CARDOSO, F. H.; FALETTO, E. Dependência e desenvolvimento na América Latina. 8. ed. Rio de Janeiro: Civilização Brasileira, 2004. p. 135.

COSTA, E. A política salarial no Brasil: 1964-1985. São Paulo: Boitempo, 1997. p. 23-56.

DRAIBE, S. Rumos e metamorfoses: um estudo sobre a constituição do Estado e as alternativas da industrialização no Brasil, 1930-1960. São Paulo: Paz e Terra, 1985. p. 59-135.

DREIFUSS, R. A. 1964: a conquista do Estado. 2. ed. Petrópolis: Vozes, 1981. p. 75-106.

FERNANDES, F. A revolução burguesa no Brasil: ensaio de interpretação sociológica. 5. ed. São Paulo: Globo, 2011.

FERREIRA, J.; GOMES, A. C. 1964: o golpe que derrubou um presidente, pôs fim ao regime democrático e instituiu a ditadura no Brasil. Rio de Janeiro: Civilização Brasileira, 2014.

FICO, C. Versões e controvérsias sobre 1964 e a ditadura militar. Revista Brasileira de História, v. 24, n. 47, p. 48-55, 2004. 
FONSECA, P. C. D. Vargas: o capitalismo em construção. São Paulo: Brasiliense, 1999. p. 428-464.

FONSECA, P. C. D. Sobre a intencionalidade da política industrializante no Brasil na década de 1930. Revista de Economia Política, v. 23, n. 1, 2003.

FONSECA, P. C. D. Legitimidade e credibilidade: impasses da política econômica do governo Goulart. Estudos Econômicos, v. 34, n. 3, p. 619-620, 2004.

FONSECA, P. C. D. Desenvolvimentismo: a construção do conceito. In: DATHEIN, R. (Org.). Desenvolvimentismo: o conceito, as bases teóricas, as políticas. Porto Alegre: Ed. UFRGS, 2015.

JESSOP, B. Accumulation strategies, state forms and hegemonic projects. In: CLARKE, S. (Org.). The state debate. London: Macmillan, 1991. p. 140-162.

MELLO, J. M. C.; BELLUZZO, L. G. M. Reflexões sobre a crise atual. In: BELLUZZO, L. G. M.; COUTINHO, L. Desenvolvimento capitalista no Brasil. Campinas: Unicamp, 1977. p. 146-150.

OLIVEIRA, F. Crítica à razão dualista. São Paulo: Boitempo, 2003.

POULANTZAS, N. Poder político e classes sociais. São Paulo: Martins Fontes, 1986.

SCHLABITZ, C. J. A economia política do salário mínimo no Brasil. 2014. Tese (Doutorado) - Faculdade de Ciências Econômicas, Universidade Federal do Rio Grande do Sul, Porto Alegre, 2014.

SIMONSEN, M. H. Inflação: gradualismo x tratamento de choque. Rio de Janeiro: Apec, 1970 .

TAVARES, M. C.; SERRA, J. Além da estagnação. In: TAVARES, M. C. Da substituição de importações ao capitalismo financeiro. 2. ed. Rio de Janeiro: Zahar, 1973. p.175-206.

Recebido em: 23/06/2017.

Aceito em: 30/09/2018.

(cc) BY 
